\title{
On Current Situation and Perfecting Measures of Administrative Supervision System in China
}

\author{
Mengyao Li \\ School of Government, Peking University, Beijing, 100000, China
}

Key words: Administrative supervision system, Problems, Perfecting measures.

\begin{abstract}
China's administrative supervision system plays an important role in the quality management of civil servants and the transformation of government functions, and also affects the overall development of the country. However, at present, administrative supervision system in China still has many defects, unable to improve the quality of administrative supervision and management and play its various functions. Therefore, relevant departments must fully analyze problems of administrative supervision system, and take effective measures to enhance the efficiency of our administrative supervision system.
\end{abstract}

\section{Introduction}

In the development of China's administrative supervision departments, relevant institutions must pay attention to the perfection of the administrative supervision system, and rationally optimize work behaviors of the administrative supervision department, to promote the government's acting by law, rationally transform government functions, enhance the effectiveness of civil servant quality education, build the national core talent team, and develop in a better direction.

\section{Analysis on current situation of our administrative supervision system}

In the development of administrative supervision departments in our country, the administrative supervision system still has some problems, such as, the imperfect supervision system, weak functions of the supervision system, difficult to meet the needs of modern social development and unable to promote the harmonious progress of society.

First, the administrative supervision system is less functional. With the development of our administrative supervision department, we have formed a diversified supervision system, and clarified the main body and the way of administrative supervision; therefore, we can broaden the channels of administrative supervision. However, in the practical work, our government agencies have not yet clarified the relationship between administration and supervision, and cannot define the main body of administrative supervision. In different regions, there are supervision authority and supervision form defects, and the administrative supervision procedures and scope cannot be specified. Part of government departments cannot do a good job of their own roles in administrative supervision, and cannot form a perfect administrative supervision organism through coordination and interaction, resulting in lower quality of their work. Departments in charge of anti-corruption during the administrative supervision include discipline inspection agencies, government supervision agencies, and affiliated procuratorate institutions, etc. clarification of the duty scope of administrative supervision bodies, can effectively specify the severity of disciplinary violations, and to give some supervision authority. For discipline inspection agencies, their job is to supervise party members, and timely figure out problems of party members in government departments. Anti-corruption sectors deal with corruption and bribery and other illegal acts, and define the degree of violation. However, in 
the actual work of our administrative supervision departments, disordered functions still exist, resulting in that more than one department deal with the problem and various conflicts and contradictions may rise from the trial or investigation of the case.

Second, the administrative supervision lacks sufficient independence. China's administrative supervision bodies will be subject to the executive authority in the actual development, difficult to enhance the effectiveness of supervision work. This is mainly because the rights and status of some administrative supervision bodies have not yet defined, and will be easy to be ignored. On the one hand, relevant departments cannot specify the independence of supervision bodies, and cannot endow them independent rights; therefore it is difficult to enhance the efficiency of the administrative supervision. On the other hand, although in China's relevant laws and regulations, it is expressly stipulated that administrative supervision bodies have to have independent rights during acting in accordance with the law, and cannot be subject to interference or influence of any administrative organ to ensure the scientificity of activities of administrative supervision bodies. However, in the actual work, some administrative supervision bodies still will be subject to interference and constraint of other administrative supervision departments, resulting in lack of adequate work independent, and even some problems difficult to solve.

Third, administrative supervision laws and regulations are imperfect. In the development of China's administrative supervision and management departments, it is necessary to require departments to act according to law, regard laws and regulations as the carrier, and comprehensively carry out various types of administrative supervision activities. However, due to relatively slow legislation in terms of China's administrative supervision, supply of laws and regulations is not sufficient, and the work efficiency cannot be improved. First of all, China's relevant departments have not yet built a complete laws and regulations, and cannot improve the effectiveness of administrative supervision work, difficult to achieve the desired management purposes. Second, some administrative supervision departments do not carry out various activities according to relevant laws and regulations, and even there are not relative laws or rules to be followed, such as, in terms of supervision rights of the People's Congress, there are not proper laws and regulations. In the relevant work, due to the lack of operational system and norms, it is difficult to enhance the efficiency and quality of NPC's supervision on legal cases, and even long-term progress of administrative supervision will be affected. Finally, administrative supervision bodies in our country lack proper protection measures, and they are often blocked or retaliated or even beat by some parties. The enthusiasm of the staff declines and the quality of administrative supervision cannot be improved comprehensively.

Fourth, the whole-process supervision system does not exist. China's administrative supervision departments have not yet built the whole-process work system and related issues cannot be prevented. First of all, relevant departments do not develop a pre-supervision system, unable to prevent all kinds of administrative problems according to the actual situation of administrative supervision objects, and difficult to play their own supervisory role. Second, relevant departments do not develop a sound in-process supervision system, unable to control the development of administrative cases, resulting in a variety of difficult problems. Finally, the administrative supervision department working manners are too single, only paying attention to the subsequent punishment, but unable to play its functions. Although the supervision objects are subject to certain punishment, but it has bad influence on the society, and also leads serious economic losses.

Fifth, lack of high-quality talent team. The administrative supervision departments do not attach importance to the construction of qualified talent team, and cannot actively introduce high-quality professionals. Most of the staff is in the older age, and they lack innovation ability, and cannot establish a correct concept of work. In law enforcement, they cannot follow relevant principles, and it is difficult to improve the level of law enforcement work, and enhance work results. At the same time, in the actual work, some administrative supervisors have not formed a unified law enforcement team, and they cannot use advanced work to improve the quality of administrative supervision ${ }^{[1]}$. 
Sixth, the public lacks sufficient awareness of participation. In the actual implementation of administrative supervision work, the public participation is more important; however, influenced by the traditional concept, some citizens cannot properly exercise their own supervision rights, or actively participate in the administrative supervision work. At the same time, when citizens' interests are violated by administrative departments, they do not have the awareness to appeal or report, and cannot use the correct behavior to carry out the relevant work; therefore, it is difficult to enhance the application value of administrative supervision system, even resulting in various difficult problems.

\section{Perfecting measures of administrative supervision system}

In the development of administrative supervision departments, we must improve relevant management system, and use various types of work ways to enhance the quality of administrative supervision. Specific measures are as follows.

\section{Establish perfect laws and regulations to promote legislation}

Relevant departments need to develop sound laws and regulations to promote the legal development according to the actual characteristics and needs of administrative supervision. First of all, relevant departments need to set standard administrative supervision procedures, and abandon traditional concept of legislation, to break the limitations of blind legislation, and enhance the operability of laws and regulations, and the development effect. Second, relevant departments are required to speed up legislative process, strictly develop "rule of law" program, and based on relevant system, construct a special administrative supervision legal system, to effectively meet the administrative supervision needs. Third, relevant departments need to comprehensively analyze the legal requirements on the administrative supervision departments, to ensure the feasibility of legal items, promote supervision departments to build clean and honest government, and enhance the standardization of administrative supervision. Finally, relevant departments need to intensify the legal construction work, to build a sound management program and promote the development of administrative supervision system ${ }^{[2]}$.

\section{Develop sound government supervision coordination system}

Administrative supervision departments need the coordination of government departments, to build a sound supervision mechanism. First of all, administrative supervision departments should take government departments as the main body, under the coordination, to enhance common development effectiveness, give full play to supervision of government departments, and achieve good results. Second, complex administrative supervision cases require the collaborative management between relevant departments and government departments. It is necessary to intensify supervision and inspection efforts, such as setting up a special inspection and inspection system, adopting various means to carry out relevant work to strengthen anti-corruption efforts, and setting up coordination groups to enhance the quality of their work. Third, administrative supervision departments need to strengthen the coordination between the public security organs, and inspection organs, to form a whole administrative supervision organization, give full play to the leadership and supervision of various departments and enhance the quality of administrative supervision work. Finally, administrative supervision departments require the unified coordination of the party committee, to gradually improve the supervision, guidance, coordination, and achieve the desired purpose of management ${ }^{[3]}$.

\section{Intensify efforts of specialized organs}

Administrative supervision departments must intensify efforts of specialized organs to enhance the quality of work in various departments. First of all, pay enough attention to the work of the local supervisory organs, and require leaders to enough emphasize administrative supervision work to enhance the quality of administrative supervision. At the same time, set up an independent supervision system to enhance the quality of specialized organs. Second, enhance the authority of various departments, to ensure the independence of the administrative supervision bodies in the 
coordination of the work, so that in the actual work they will not be affected by other organs, to avoid case interference, and enhance the work intensity. Finally, relevant departments should perfect the administrative supervision system, and specify the work of various organs to improve the quality of their work ${ }^{[4]}$.

\section{Innovate government supervision mechanism}

Government departments at all levels have the responsibility of administrative supervision. They shall pay much attention to their own responsibilities, to ensure the administrative work of affiliated departments and subordinates, enhance the quality of their work and strengthen the effectiveness of administrative supervision. First of all, ensure all kinds of regulatory documents filed, and carry out relevant work according to the rules and regulations for the fundamental prevention of administrative violations. Second, conscientiously implement relevant laws and regulations, improve the work quality, learn from foreign successful system, quickly resolve the controversial system, and ease the internal contradictions. At the same time, coordinate the relationship between the government and the masses, and effectively improve the work quality. Finally, improve administrative compensation system, to enhance the efficiency and effectiveness of the system implementation in the event of administrative compensation ${ }^{[5]}$.

\section{Develop sound system for administrative supervision responsibility}

Current administrative supervision system has complex characteristics, and the supervision form is diversified, but there still exist problems in terms of responsibility-ascertaining, such as, it is difficult to effectively implement relevant responsibilities. Therefore, relevant departments shall give full play to the role of administrative supervision, clarify job responsibilities, develop specific work plan, and effectively strengthen the management efforts. At the same time, ensure that the internal staff establishes the concept of self-restraint, and in the event of problems, administrative supervision responsibility can be investigated, to gradually improve the work quality.

\section{Perfect public supervision system}

Relevant departments shall improve public supervision system, to help citizens establish the correct concept, broaden supervision channels of citizens. According to the law, carry out election and decision-making activities to ensure that rights of citizens of to know and participate in administrative matters, and based the views of citizens, establish and improve relevant management system. First of all, help citizens establish the correct concept, and guide citizens to consciously participate in all kinds of administrative activities, to change their traditional ideas, and enhance the work quality. Second, increase publicity and education, and use modern media for citizens to explain administrative supervision related knowledge, to make it take social responsibility, and play its own supervisory role. Finally, build relevant laws and regulations, and use legal channels to protect the rights and safety of citizens, to avoid safety threat issues in case of citizens reporting or supervising. At the same time, ensure that openness degree of government information, enhance the transparency of data information, and improve the quality of administrative supervision.

\section{Build high-quality talent team}

Administrative supervision departments must pay attention to talent development work, to ensure the work quality efficiency in line with relevant provisions. First of all, employ supervisors with high professional quality and certain ideological awareness, require them in practical work, to face their own work, and improve the work quality. At the same time, conduct training on professional quality and ideology and policy, to ensure the development of high-quality and professional-level administrative supervision talent team. Second, in the actual work, administrative supervisors should establish the correct ideas, and strengthen their own moral cultivation and legal awareness, to enhance their sense of responsibility and work quality. Again, the staff should develop good administrative ethics, actively participate in various activities, and will not be affected by the bad practice. Finally, relevant departments should carry out training on professional knowledge and legal 
knowledge for the staff, to make them competent and capable, and comprehensively optimize the administrative supervision and decision-making system to achieve the desired development goals.

\section{Conclusions}

In the development of our administrative supervision departments, we must pay attention to the perfection of work system, discover all kinds of problems in time, take effective measures, formulate perfect and clear-cut responsibility program, improve the work quality and enhance citizen's administrative supervision, and safeguard their legitimate rights and interests.

\section{References}

[1] Yan Naici. Approach Selection for Perfecting Our Administrative Supervision System, Youth Literator, 2012 (35): 248.

[2] Chen Xiuping, Feng Liping. The Status Quo and Perfection of China's Rural Environmental Administrative Law Enforcement, Liaoning Agricultural Sciences, 2014 (6): 69-71.

[3] $\mathrm{Hu}$ Jihua. Problems and Countermeasures of China's Environmental Administrative Law Enforcement, Legal System and Society, 2015 (31): 147-149.

[4] Li Xianjun. Approach Analysis on Perfecting China's Administrative Supervision System, Commodities and Quality · Academic Observation, 2012 (9): 254.

[5] Zhang Ou. Problems and Countermeasures of China's Administrative Supervision, Management Observation, 2013 (33): 161-162. 